\title{
Rapidly destructive hip disease following ipsilateral hemiparesis: report of two cases
}

\author{
MARTIN PATTRICK AND MICHAEL DOHERTY
}

From the Rheumatology Unit, City Hospital, Nottingham

SUMmaRY Two patients who developed rapidly destructive arthropathy of the hip following ipsilateral hemiparesis are described. The possible significance of this association is discussed.

Key words: osteoarthritis, coxarthrosis, analgesic hip, destructive arthropathy, apatite associated destructive arthropathy, Charcot arthropathy.

There have been several reports concerning the effects of neurological deficit on the subsequent development of a variety of joint diseases. ${ }^{1-10}$ Most commonly it has been concluded that either a central $^{1-6}$ or peripheral ${ }^{7-10}$ lesion protects the affected limb from subsequent development of arthropathy. This sparing effect has been attributed to disuse with subsequent reduction in damaging mechanical factors. ${ }^{2310}$ The converse effects of neurological deficit on established joint disease are less well recorded; there are two reports, however, of hemiparesis resulting in a flare of rheumatoid synovitis confined to the paretic side. ${ }^{11} 12$

Apatite associated destructive arthropathy is a recently recognised form of 'joint failure' characterised by severely painful and rapid progression to joint destruction. Radiographic features include marked cartilage and bone attrition with paucity of osteophytes and cysts. ${ }^{13}$ Synovial fluid from such joints is typically non-inflammatory and contains plentiful alizarin red staining particles identified as apatite. ${ }^{1314}$ The predilection for this condition to affect large joints of the elderly is striking, ${ }^{13-16}$ but the pathogenesis remains obscure. ${ }^{1314}$

Two elderly patients who developed unilateral rapidly destructive coxarthrosis following ipsilateral hemiparesis are described. The clinical, radiographic, and histological characteristics of their arthropathy were typical of those described for apatite associated destructive arthropathy. The relevance of this observation to the pathogenesis of rapidly destructive arthropathy is discussed.

Accepted for publication 24 November 1986.

Correspondence to Dr Martin Pattrick, Rheumatology Unit, City Hospital, Hucknall Road, Nottingham NG5 1PB.

\section{Case reports}

CAS E 1

A previously fit 58 year old right handed window cleaner developed an acute left hemiparesis. He made an excellent recovery but was left with mild residual hemiparesis and increased tone on the left side. Hypertension was diagnosed and adequately treated by bendrofluazide $5 \mathrm{mg}$ daily. Fifteen years later (age 73 years) he developed insidious onset of pain and stiffness in the left hip; radiographs showed bilateral superior pole joint space narrowing with sclerosis and osteophyte formation. His symptoms were readily controlled by physiotherapy and naproxen $500 \mathrm{mg}$ twice a day.

At age 77 years he developed a second, more severe hemiparesis causing profound weakness and transient sensory disturbance, again on the left side. He made only slow improvement during the next three months and complained of severe exacerbation of left hip symptoms on attempted weight bearing, and developed night pain sufficient to interrupt sleep. His symptoms did not respond to naproxen $1 \mathrm{~g}$ daily and paracetamol $4 \mathrm{~g}$ daily, and in an attempt to control his severe pain he inadvertently took multiple drug therapy: for four weeks he took naproxen $1 \mathrm{~g}$ and indomethacin slow release $150 \mathrm{mg}$ daily. Eight months after onset of this severe pain he was admitted to hospital with bleeding from multiple superficial gastric erosions. There was no history of significant trauma nor had he received steroids. Examination at this time showed marked painful reduction in all movements of the left hip. There was mild, pain free restriction of internal rotation and flexion of the right hip, but apart from several Heberden's nodes, more marked on the 
right, there was no evidence of arthropathy elsewhere. There was $4 / 5$ pyramidal weakness affecting the left arm and leg, but no sensory abnormalities. Radiographs showed the previously noted changes of superior pole osteoarthritis on the right; the left, however, showed apparent widening of the joint space, marked bone attrition affecting both femoral and acetabular components, and absence of osteophytes and cysts (Fig. 1). Plain radiographs of knees and hands (to include wrists) showed mild changes of osteoarthritis in several interphalangeal joints: no chondrocalcinosis was apparent. Investigations included; haemoglobin $12 \cdot 8 \mathrm{~g} / \mathrm{dl}(128 \mathrm{~g} / \mathrm{l})$, erythrocyte sedimentation rate $37 \mathrm{~mm} / \mathrm{h}$, serum urea $11.1 \mathrm{mmol} / \mathrm{l}$ (normal range $1.0-6.5 \mathrm{mmol} / \mathrm{l}$ ), serum creatinine $221 \mu \mathrm{mol} / \mathrm{l}$ (normal range $60-120 \mu \mathrm{mol} / \mathrm{l}$ ), serum electrolytes, glucose, magnesium, calcium, uric acid, iron, iron binding capacity, ferritin, vitamin $B_{12}$, red cell folate, liver and thyroid function tests were within normal limits. Rheumatoid factor and serological tests for treponemal infection were negative.

Sequential use of various non-steroidal antiinflammatory agents and analgesics failed to control his symptoms, and on general medical grounds he was considered unsuitable for hip replacement.

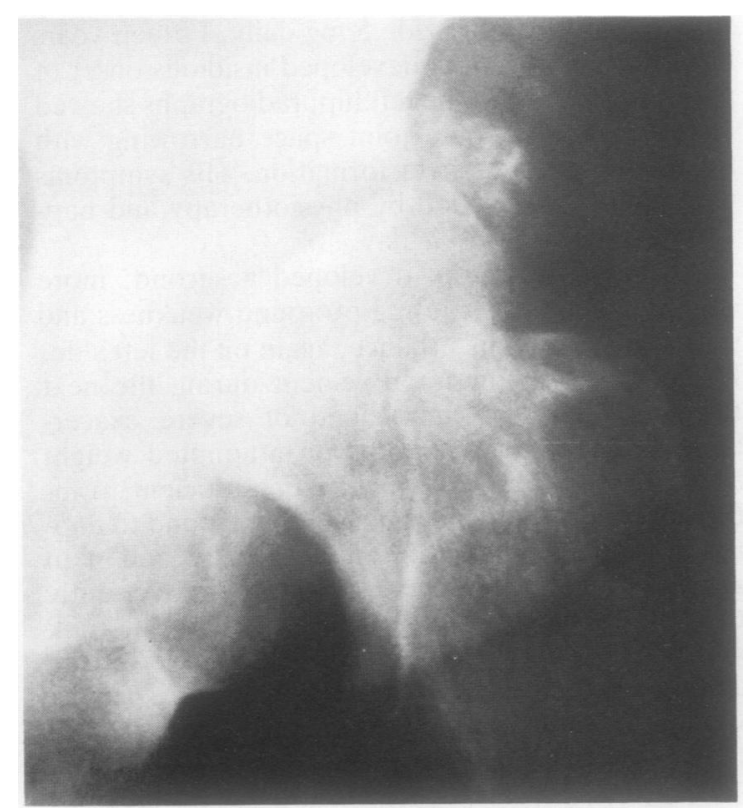

Fig. 1 Left hip radiograph of patient 1 taken eight months after onset of severe symptoms, showing marked bone attrition affecting both sides of the joint, apparent widening of the joint space, calcific debris, and absence of cyst and osteophyte.

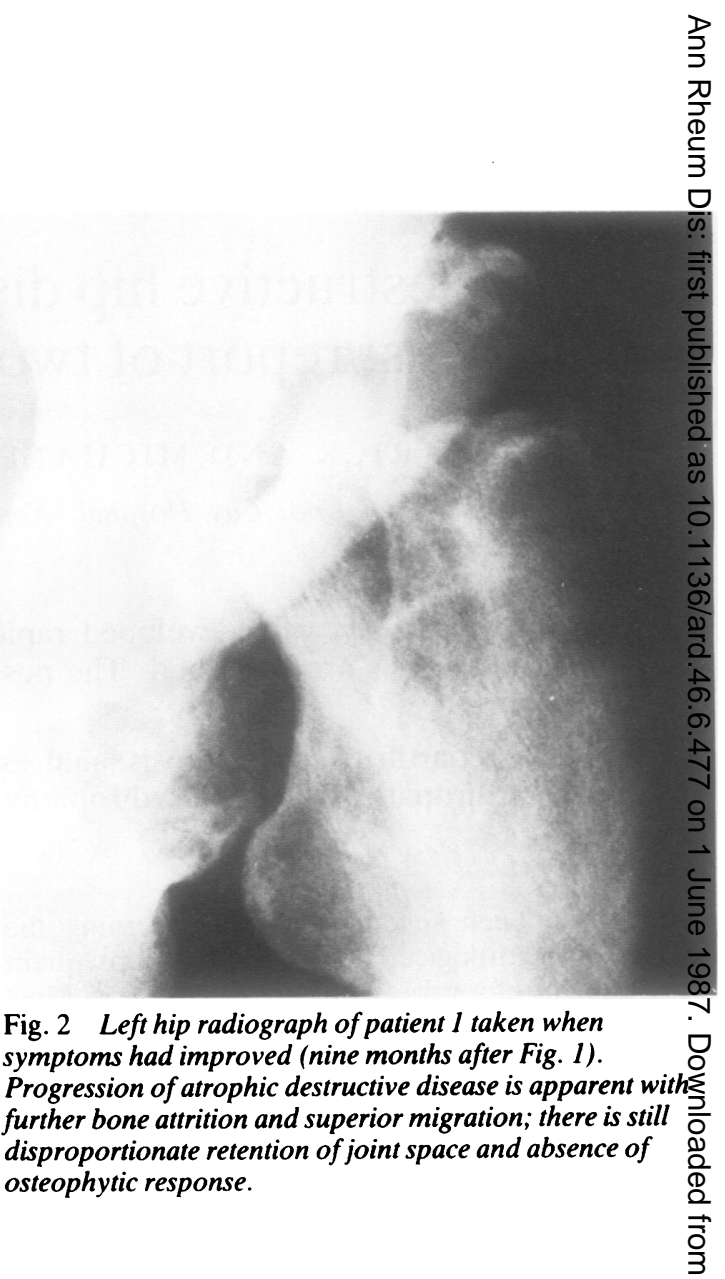

Over the succeeding nine months, however, his hip pain steadily improved, despite further radiographie. progression (Fig. 2). Twelve months after the second hemiparesis he is ambulant and indepen dent, experiencing hip pain only after prolonge weight bearing.

CASE 2

A 68 year old right handed woman developed a acute onset of left hemiparesis. She had receive bendrofluazide $5 \mathrm{mg}$ daily for hypertension for. three years, and had a three year history of bilaterafe hip pain managed successfully by weight reduction. physiotherapy, and occasional paracetamol. HiR radiographs performed two years before her hem $\%$ paresis showed moderate bilateral osteoarthritis with central narrowing, sclerosis, and cyst form tion. She made good functional recovery from he hemiparesis but was left with residual increased tone, brisk reflexes, extensor plantar response, and mild spastic gait on the left. No sensory signs were elicited at any stage, and the pyramidal weaknes had largely resolved after two months.

Three months after the onset of her hemipares she developed marked increase in left hip symps 
toms, with predominant pain on usage and moderate night pain. There was no obvious predisposing trauma. Attempts to control her severe progressive pain with non-steroidal anti-inflammatory agents and analgesics were unsuccessful, and she was referred for orthopaedic opinion. Examination three months after exacerbation of symptoms disclosed marked painful restriction of all left hip movements. The right hip showed only pain free limitation of internal rotation and flexion and apart from mild bilateral Heberden's nodes there was no evidence of arthropathy elsewhere. No new neurological signs were elicited. Hip radiographs showed no change from the previously recorded osteoarthritis on the right, but on the left there was severe destructive change affecting both femoral and acetabular components (Fig. 3). Haematological and biochemical screening showed no underlying predisposing abnormality.

At total hip replacement five weeks later marked attrition of cartilage and bone was confirmed macroscopically. Histological examination showed hyperplastic villous synovial tissue containing chronic inflammatory cells, macrophages laden with haemosiderin (Perl's stain), and occasional multinucleate giant cells. Numerous irregular intrasynovial bony fragments were present within collagen

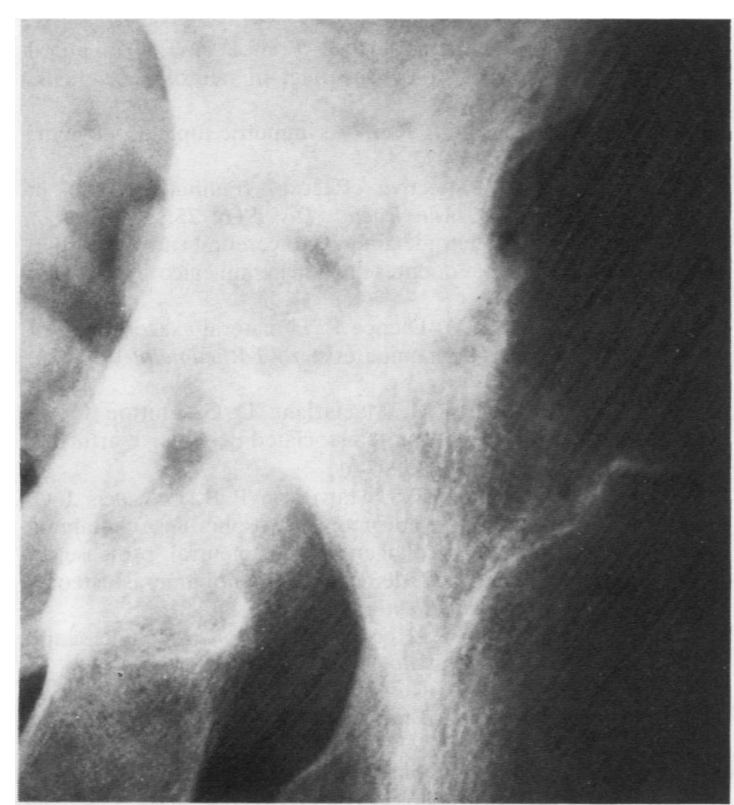

Fig. 3 Left hip radiograph of patient 2 taken six months after onset of hemiparesis, showing severe atrophic disease with marked attrition of both acetabular and femoral components. staining material, the latter often hyalinised. Alizarin red staining showed further, smaller calcific particles, which frequently costained with van Gieson's stain. No birefringent crystals were identified and there was no microscopic or culture evidence of tuberculous or pyogenic infection.

Nine months after surgery the patient remains mobile, independent, and pain free.

\section{Discussion}

Two patients who developed rapidly destructive hip disease following ipsilateral hemiparesis are described. Both had recorded pre-existing hip osteoarthritis which had been stable before the onset of the neurological event. Neither patient had received steroids or sustained previous hip trauma, and a full clinical and metabolic screen failed to disclose associated or underlying disease. In the absence of other recognised predisposition to rapidly destructive arthropathy, the close temporal relationship to hemiparesis, the previously quiescent joint disease, and the striking lateralisation strongly support a causal rather than chance association. To our knowledge this is the first report of such an occurrence.

A number of reports describe rapidly destructive arthropathy of large joints under a variety of titles including 'analgesic hip', 'indomethacin hip', ${ }^{17-22}$ apatite associated destructive arthropathy, ${ }^{13}$ Milwaukee shoulder syndrome, ${ }^{14}$ lytic arthropathy, ${ }^{23}$ senile haemorrhagic arthrosis, ${ }^{24}$ and idiopathic destructive arthropathy. ${ }^{25}$ The presence of plentiful apatite crystals in synovial fluid and tissues has been emphasised, ${ }^{13} 1426$ but the pathogenic significance of these particles in rapid joint destruction remains unknown. ${ }^{131426}$. Although the factors that predispose to rapid joint destruction are unclear, advanced age, being female, and the occurrence of calcium pyrophosphate dihydrate crystal deposition either within the involved joints or at distant sites have all been incriminated ${ }^{27-30}$; the possible contributory role of non-steroidal anti-inflammatory agents remains controversial. ${ }^{31}$ Differential diagnoses that may be considered include late avascular necrosis and sepsis, though the clinical, synovial fluid, and radiographic features most closely resemble Charcot arthropathy. ${ }^{31}$ Two radiographic appearances of Charcot arthropathy are recognised; a 'hypertrophic' type characterised by exuberent sclerosis, osteophyte formation, abundant osseous debris, and dissolution of normal joint architecture; and an 'atrophic' form with extensive bone resorption without evidence of accompanying bone repair. ${ }^{32-35}$ It has been suggested that the atrophic form represents an earlier stage of the disease 
before repair has begun. There are two main theories of causation: firstly, that reduced pain and proprioception lead to excessive mechanical trauma that disrupts joint tissue, ${ }^{36-38}$ and secondly, that abnormality of neurovascular control disturbs bone and cartilage nutrition. ${ }^{39} 40$ The importance of adjacent bone fracture, a not uncommon early feature, remains uncertain. ${ }^{38}$ Although generally regarded as a characteristically pain free condition, pain may be a prominent symptom in up to $30 \%$ of patients $^{3941}$ and was indeed emphasised by Charcot in his original description. ${ }^{42}$

In our two patients their advanced age, the rapid severe clinical and radiographic progression, the individual atrophic $x$ ray features, the synovial histology in case 2, and the absence of sepsis or other cause of joint destruction are fully consistent with a diagnosis of apatite associated destructive arthropathy, idiopathic destructive arthropathy, or 'analgesic hip'. The radiographic appearance in isolation is also indistinguishable from atrophic Charcot arthropathy ${ }^{13}$ : clinical points of differentiation, however, were the prominence of pain and the restriction rather than increase of joint mobility. Radiographic similarity between apatite associated destructive arthropathy and atrophic Charcot arthropathy has previously been noted, ${ }^{13}$ and it is therefore of interest that apatite associated destructive arthropathy, an uncommon arthropathy of the elderly, should develop in the hips of both our patients following ipsilateral hemiparesis. Rapidly destructive arthropathy is not a recognised complication of hemiparesis: both our patients had predominant motor impairment, only transient clinical sensory abnormality, and severe pain which inhibited even normal loading of the joint. A damaging effect from the non-steroidal antiinflammatory agents used by these patients cannot be excluded, though the marked asymmetry coinciding with the neurologically affected side suggests a more important neurogenic cause.

Although previous reports emphasise a predominantly sparing effect of neurological deficit on subsequent development of new rheumatic disease,${ }^{1-10}$ the effect of hemiparesis on pre-existing joint disease may be to cause exacerbation. ${ }^{11} 12$ Both our patients had bilateral osteoarthritis of the hip and shortly following hemiparesis the hip on the affected side entered a rapidly destructive phase with marked bone and cartilage attrition. Although we cannot deduce the precise relation between hemiparesis and rapidly destructive arthropathy in these two cases, the abrupt onset, rapid progression, severe tissue loss, and non-inflammatory features are most compatible with a neurovascular theory of causation. ${ }^{30}$ More subtle age related neuro- vascular abnormality may well underly the pathogenesis of apparently idiopathic destructive arthro pathy of the elderly.

The marked clinical improvement, despite radio-음 graphic progression in patient 1 (Figs 1 and 2), is of further interest and contrasts with the poor outcomes reported in patients with apatite associated destruc $\frac{\mathbb{\Omega}}{2}$ tive arthropathy. ${ }^{43}$ The second patient underwente surgery shortly after entering the rapid phase of joint destruction. Long term prospective studies are still required to determine the natural history of idiopathic destructive arthropathy of the elderly.

We would like to thank the Arthritis and Rheumatism Council for financial support.

\section{References}

1 Jacqueline $F$. Un cas de polyarthritis evolutive a localisation controlatérales d'une hémiplégie. Rev Rhum Mal Osteoartic1953; 20: 324-5.

2 Thompson M, Bywaters E G L. Unilateral rheumatoid arthritis following hemiplegia. Ann Rheum Dis 1962; 21: 370-7.

3 Bland $\mathrm{J}$ H. Eddy W M. Hemiplegia and rheumatoid hemiarthri- $\overparen{D}$ tis. Arthritis Rheum 1968; 11: 72-80.

4 Coste F. Forestier J. Hémiplégie et nodosités d'Heberderpo controlatérales. Bull Mem Soc Med Hop Paris 1935; 51: 772-6:

5 Glynn J J. Clayton M L. Sparing effect of hemiplegia on tophaceous gout. Ann Rheum Dis 1976; 35: 534-5.

6 Forestier J. Rhumatisme d'Heberden chez une hémiplégique Lésions articulares limitées au côté sain. Rev Neurol (Paris) 1935: 63: 442-8.

7 Glick E N. Asymmetrical rheumatoid arthritis after poliomyelitis. $\mathrm{Br}$ Med J 1967; ii: 26-8.

8 Yaghamai I, Rooholamini J M, France H F. Unilatera $\overrightarrow{\bar{D}}$ rheumatoid arthritis: protective effect of neurologic deficits AJR 1977; 128: 299-301.

9 Cosgrave P M, Lewkonia R M. Asymmetric tophaceous gout J Rheumatol 1979; 6: 472-4.

10 Kamermann J S. Protective effect of traumatic lesions ir rheumatoid arthritis. Ann Rheum Dis 1966; 25: 361-73.

11 Nava P. Artrite reumatoide antiga icto cerebral surto evolutivo agudo nas articulacoes doentes do lado hemiplegico. Brasil-Mer 1953; 67: 318-21.

12 Pattrick M, Doherty M, Dieppe P. Unilateral exacerbation of rheumatoid arthritis by hemiparesis. Br J Rheumatol 1984; $23_{\circ}^{\circ}$ 107-9.

13 Dieppe $P$ A, Doherty M, Macfarlane D G, Hutton C WD Bradfield J W, Watt I. Apatite associated destructive arthritis을 Br J Rheumatol 1984; 23: 84-91.

14 McCarty D J, Cheung H S, Halverson P B, Gavancis J C 'Milwaukee shoulder' syndrome: microspherules containing hydroxyapatite, active collagenase and neutral protease in patients with rotator cuff defects and glenohumeral osteoar thritis. Semin Arthritis Rheum 1981; 11: 119-21.

15 Lamboley $\mathrm{C}$, Bataille $\mathrm{R}$, Rosenberg F, et al. L'épaule sénile hémorrhagique. Rheumatologie 1977; 29: 323-30.

16 Lequesne M, Fallut M, Coulomb R, Magnet J L, Strauss J L'arthropathie destructice rapide de l'épaule. Rev Rhum Ma? Osteoartic 1982; 49: 427-37.

17 Coke $H$. Long term indomethacin therapy for coxarthrosis Ann Rheum Dis 1967; 26: 346-7.

18 Arora J S, Maudsley $\mathrm{R}$ A. Indomethacin arthropathy of hips Proc $R$ Soc Med 1968; 61: 669.

19 Allen E H, Murray O. Iatrogenic arthropathies. Proceedings of the Association of Radiology. Amsterdam: Excerpta Medica1971: 249: 204-10. (International Congress Serics.) 
20 Milner J C. Osteoarthritis of the hip and indomethacin. J Bone Joint Surg [Br] 1973; 54: 752.

21 Solomon L. Drug induced arthropathy and necrosis of the femoral head. J Bone Joint Surg [Br] 1973; 55: 246-61.

22 Hauge M F. Hofteleddsartrose-indometacin. Tidsskr Nor Laegeforen 1975; 95: 1594-6.

23 Rubens-Duval A, Kaplan G. Les lésions synoviales de l'arthrose et des arthropathies lytiques. Rev Rhum Mal Osteoartic 1972; 39: 691-6.

24 de Sèze $M$. L'épaule sénile hémorragique. In: L'actualité rhumatologique. Vol 1. Paris: Expansion Scientifique Francaise, 1968: 107-15.

25 Campion G V, McCrae F. Alwan W, Watt I, Bradfield J, Dieppe $P$ A. Idiopathic destructive arthritis (IDA) of the shoulder in elderly women. Semin Arthritis Rheum (in press).

26 Nuki G. Apatite associated arthritis. Br J Rheumatol 1984; 23: 81-3.

27 Richards A J, Hamilton E B D. Destructive arthropathy in chondrocalcinosis articularis. Ann Rheum Dis 1974; 33: 196203.

28 Menkes C J, Simon F. Delriew F, Forest M, Delbase F. Destructive arthropathy in chondrocalcinosis articularis. Arthritis Rheum 1976; 19(suppl 3): 329-48.

29 Gerster J C, Vischer T L, Fallet G H. Destructive arthropathy in generalised osteoarthritis with articular chondrocalcinosis. $J$ Rheumatol 1975; 2: 265-9.

30 Menkes C J, Decraemere W, Postel M, Forest M. Chondrocalcinosis and rapid destruction of the hip. $J$ Rheumatol 1985; 12: 130-3.
31 Doherty M, Holt M. MacMillan P. Watt I, Dieppe P A. A reappraisal of 'analgesic hip'. Ann Rheum Dis 1986; 45: 272-6.

32 Delano P J. The pathogenesis of Charcot's joint. AJR 1946; 56: 189-200.

33 Knaggs R L. Charcot joints. In: Knaggs R L, ed. Inflammatory and toxic diseases of bone. Bristol: Wright, 1926: 105-19.

34 Steindler A. The tabetic arthropathies. JAMA 1931: 96: 250-5.

$35 \mathrm{McNeel} D$ P. Elmi G. Charcot joint of the lumbar spine. $J$ Neurosurg 1969; 30: 55-61.

36 Bruchner F E, Howell A. Neuropathic joints. Semin Arthritis Rheum 1972; 2: 47-69.

37 Feldman F. Neuropathic osteoarthropathy. In: Margulis A R, Gooding C A, eds. Diagnostic radiology 1977. San Francisco: University of California, 1977: 397-408.

38 Johnson J T H. Neuropathic fractures and joint injuries. Pathogenesis and rationale of prevention and treatment. $J$ Bone Joint Surg [Am] 1967; 49: 1-30.

39 Brower A C. Allman R M. Pathogenesis of the neurotrophic joint: neurotraumatic $v$ neurovascular. Radiology 1971; 139: 349-54.

40 Brower A C, Allman R M. The neuropathic joint: a neurovascular bone disorder. Radiol Clin North Am 1981; 19: 571-80.

41 Katz I, Rabinowitz J G, Dziadiw R. Early changes in Charcot's joints. AJR 1961; 86: 965-74.

42 Charcot J M. Sur quelques arthropathies qui paraissent dépendre d'une lesion du cerveau ou de la moelle épinière. Arch Physiol Norm et Pathol 1868; 1: 161-78.

43 Lequesne M, de Sezes, Amouroux J. La coxarthrose destructice rapide. Rev Rhum Mal Osteoartic 1970; 37: 721-33. 